\title{
INTERNATIONAL RISK ASSESSMENT \\ AND DECISION MAKING \\ IN DUTCH SMALL AND \\ MEDIUM SIZED ENTERPRISES
}

\author{
Henk van den Berg
}

Rotterdam University of Applied Sciences, Rotterdam, Holland,

e-mail: h.van.den.berg@hr.nl

"You either believe in God or you don't, and you either have an infinity of an infinitely happy life (if god exists and you belief) or you have an eart [h]ly life and die (otherwise). So the expectations of believing in God, which is infinite, exceeds the expectations of not believing, which in finite."

From Edwards, et.al (2007). Pascal's Wagner (1670) is considered being "the first well-understood contribution to decision theory"

\begin{abstract}
In this article we will discuss the process of judgment and decision-making (JDM) the management of a company goes through when they are confronted with the opportunity to operate internationally. In particular we will focus on the way country risks are incorporated in the assessment that companies make concerning the feasibility of these international opportunities. Although the literature appears to offer a systematic approach based on research, the actual JDM follows a different route, one of intuition. This will be demonstrated by research in five sectors in the Netherlands. The gap between theory and its application offers a model for an improved way of doing things by clarifying why business is only partially using the outcome of research.

Keywords: judgment and decision making, international business, international risk assessment, small and medium sized enterprises, Holland
\end{abstract}

Paper type: Research paper

\section{Introduction}

Internationalisation, like culture, is hard to define, although we are able to deal with it. It ranges from student exchange, a common research project across borders, or diplomacy to establishing a daughter company abroad. Whatever the definition, it has to do with 'crossing borders'. However, not all 'crossing borders' 
INTERNATIONAL RISK

Henk van den Berg, is internationalisation; or one should consider a holiday abroad as individual internationalisation. The definition of internationalisation depends on contexts like time and place. In this article it is even further delineated to business.

Even in business internationalisation is a rather wide concept. Indeed, the entrepreneur who starts a company wants to conquer the world but beyond the scope of his or her dream future, s/he is normally focused on a national market or even part of it. The framework for business however is rather limited. The study of international relations focuses on states, international business law focuses on legal aspects and the study of economics is not always very specific (not focused on the situation of an individual company).

On the other hand businesses are more and more forced to consider international aspects of its performance. Although, among others, Smith (1776) and Ricardo (1817) already mentioned more than two centuries ago that international business is the economic sound way to go, nowadays international trade and investment are growing in importance. The Heckscher-Ohlin theory explains that "a nation will export the commodity whose production requires the intensive use of the nation's relatively abundant and cheap factor and import the commodity whose production requires the intensive use of the nation's relatively scarce and expensive factor" (Salvatore, 2011). Additional theories that explain today's international trade and complement the Heckshcer-Ohling theory are; economies of scale, imperfect competition, differences in technological development, transportation cost and environmental standards.

Although it seems that internationalization is a natural, evolutionary concept which only has advantages, companies that want to engage in international business, need to be at their guard and consider the trade-off between risk and return in their decision making. As Baird and Thomas (1985) mentioned: "because risk is a significant determinant of foreign investment there is a need for the relevant decision makers to identify, estimate and assess the relevant risk and to respond to it." White and Fan (2006) state that the decision maker specifically needs to pay attention to country risk: "by far the most important risk context for FDI is the country environment. (...) Country risk arises from the interaction of strategies formulated and implemented by the relevant enterprise and the relevant country government. This interaction occurs within a political, economic, financial, and cultural context which is often alien to the foreign investor."

This article continues with the presentation of the relevant literature. First the field of decision making is presented after which a brief overview of country risk is presented. After the theory is discussed, the research methodology is presented. The next paragraph presents the research findings. In the end of this article the conclusions are presented and some ideas for follow up are shared with the reader. 


\section{Decision-making}

The available literature may be found in management and in decision-making research. A selection of models is presented in Table 1 after which each model is explained. The last part of this paragraph explains which model is choosen for this study and why.
INTERNATIONAL RISK

Henk van den Berg,

\begin{tabular}{|c|c|c|c|c|}
\hline & $\begin{array}{l}\text { Dyck and } \\
\text { Neubert } \\
(2009)\end{array}$ & $\begin{array}{c}\text { Ahlstrom } \\
\text { and Bruton } \\
(2010)\end{array}$ & $\begin{array}{c}\text { Goodwin } \\
\text { and Wright } \\
(2009)\end{array}$ & $\begin{array}{c}\text { Bazerman } \\
\text { and Moore } \\
(2009)\end{array}$ \\
\hline Identify the decision maker & & & $\times$ & \\
\hline Define the problem & $x$ & $x$ & & $x$ \\
\hline Identify the key decision criteria & & $x$ & $x$ & $x$ \\
\hline $\begin{array}{l}\text { Measure the performance of the } \\
\text { alternatives on the attributes }\end{array}$ & & & $x$ & $x$ \\
\hline Allocate relative weights to the criteria & & $x$ & $x$ & $x$ \\
\hline Determine the decision style & & $\times$ & & \\
\hline List solutions and develop alternatives & $x$ & $x$ & $x$ & $x$ \\
\hline Evaluate the alternatives & $x$ & $x$ & & $x$ \\
\hline Select the choice & $x$ & $x$ & $x$ & $\times$ \\
\hline Mobilize resources & & $\times$ & & \\
\hline Perform sensitivity analysis & & & $x$ & \\
\hline
\end{tabular}

Table 1.

Decision making models

Dyck and Neubert (2009) define decision making as "a choice that is made from a number of available alternatives". The process of decision-making and the steps involved in that process are described by Dyck and Neubert (2009) as a model of four phases where the first phase is the problem analysis phase and the last three phases are the problem solution phases. Ahlstrom and Bruton (2010) present a more elaborate model in eight steps.

Hardman (2009) stresses that a distinction needs to be made between decision making and judgment. He states that "judgments are essentially evaluations or estimates whereas decisions indicate an intention to pursue a particular course of action." Although Dyck and Neubert (2009) describe decision making as not 
INTERNATIONAL RISK

Henk van den Berg, an objective rational process of making choices, they assume that the irrational judgmental behaviour of the actors involved in the process of decision making will lead to a satisfactory solution and choice as a result of the working counter forces of the actors involved.

More comprehensive models of decision making are from the field of decision analysis. Where Ahlstrom and Bruton (2010) and Dyck and Neubert (2009), from the field of management, limit their theories to the fact that individuals are not rational decision makers, decision analysts like Winterfeldt and Edwards (1986) and Goodwin and Wright (2009) integrate this irrationality in the decision making model in a way that the model helps minimize the irrationality as much as possible. Winterfeldt and Edwards (1986) describe the process of decision making as a process that starts when the decision maker incurred a feeling (!) that something has to be done and/or when there is a lack of ideas about possible alternatives that can be used. The next step is to develop a set of alternatives (options) that may help to make a shift from a current state to a desired state. The options are then valued by determining to what extent each option serves each relevant alternative. Winterfeldt and Edwards (1986) explain that there is a lot of uncertainty involved in these steps. The uncertainty is the result of events that influence the options and the value of the options that are not under the control of the decision maker. Although Winterfeldt and Edwards (1986) presuppose uncertainty without any further clarification, they describe a decision tree where "the various possible outcomes of each action must be represented in some orderly way, and the linkage of each to the relevant values must be determined. In addition, the uncertainty about the outcomes of each possible action must be measured. Sometimes these uncertainties may be that important that actions intended to reduce them are useful preliminaries to final action." The process of decision making is completed by testing the characteristics of the choice with the competing characteristics with the help of a so-called sensitivity analysis. Sensitivity analysis may leave the conclusions unchanged or may be food for thought. When the conclusions remain the same, the chosen option is implemented. When the result of the sensitivity analysis gives rise to more thought, part of the decision process needs to be done again.

Goodwin and Wright (2009) developed an eight-stage model that is very similar to the model described by Winterfeldt and Edwards (1986). Goodwin and Wright (2009) assume that at the beginning of the decision making process starts when the problem is already known to the decision maker. Hence, their stage model starts with the identification of the decision maker and the alternative courses of action. Nevertheless the recognition of a problem is a very important step in the process of decision making. Dyck and Neubert (2009) state that a correctly stated problem is already half solved. Winterfeldt and Edwards (1986) 
already stated that "structuring the problem is by far the most important step in the (2009) might give a more complete overview. Bazerman and Moore (2009) suggest the following decision making model.

In this article the basis for the decision model will be the model of Bazerman and Moore (2009). This model has a better start because in our opinion that first step of defining the problem represents already half the solution. This is one of the most important steps in decision making in terms of management. Dyck and Neubert (2009) state as well that a good problem definition is already half of the solution. The disadvantage of the model of Bazerman and Moore (2009) is that they do not distinguish between the criteria relevant to the decision and the attributes relevant to the decision problem. To compensate for that shortcoming the relevant parts of the model of Goodwin and Wright (2009) have been added.

\section{Country risk assessment}

When studying the literature on country risk, it appears that country risk is an ambiguous concept. Besides the fact that not every writer uses the same description for the concept of country risk, most of them have their own specific definition of country risk (or the specific words they use for it). Subsequently, definitions are often aimed at one or more specific, but not always overlapping, areas in international business. Bouchet et al (2003) investigated the different approaches to country risk available from literature, by making a distinction between the terminologies used, the definitions of country risk, the source of the risk, the nature of the investment involved, the historical perspective, and the methodology used to assess country risks.

Because this study is aimed at identifying which country risks are used by decision makers in Dutch small and medium sized enterprises when considering international business decisions, presenting a structured overview of country risks and its specificities is considered to be influencing the respondents which is not the intention in exploratory research. Because of that we limit ourselves here by briefly discussing the definitions and taxonomy.

There are multiple definition for country risk available. According to Madura and Fox (2011) the definition of country risk is "the potentially adverse impact of a country's environment on an MNC's cash flows". The question that remains unanswered from this definition is what is meant with 'a countries environment'. Olsson (2002) makes a more specific, but also more narrow definition of country risk and defines it as: "the risk that a foreign currency will not be available to allow payment due to be paid because of a general lack of foreign currency, or a relevant government rationing what is available". This definition is very narrow because it describes the root cause of country risk as the availability of the local 
INTERNATIONAL RISK

Henk van den Berg, currency. Opposite, White and Fan (2006) give a very broad definition: "country risk is the unanticipated 'downside' variability in a key performance indicator, or significant strategic target, which results from engaging in international business transactions with an inevitable exposure to the performance and policies of a sovereign country other than the home country. It is, therefore, the risk which attaches to international business transactions as a consequence of the existence of national boundaries". With this definition White and Fan (2006) express that country risk is born out of the interaction that an enterprise has with the government of the host country. The government of the host country, for that, can be considered as part of the strategic environment of the enterprise and is the source or the starting point of country risk.

Also in typology, there are a large number of writers to refer to. Madura and Fox (2007) divide country risks in two parts; political risk factors and financial risk factors. Bouchet et. al. (2003) give a different classification of country risk based on a review of the literature. They identify three different categories of country risk; natural disaster, social-political risk, and country-specific economic risk. The most comprehensive overview of country risk is developed by White and Fan (2006).. They developed a typology of country risk by first, study the existing literature in the area of country risk. The literature was reviewed based on three criteria: "the theorist aspires the being comprehensive, the analysis is oriented to FDI and not to other decisions, the work has often been cited and continues to be cited" (White and Fan, 2006). The second source for developing a typology of country risk are ten rating agencies that use country risk in their ratings. The result of the analysis is an overview of 25 country risks, ordered under political risk, economic risk, financial risk, and cultural risk and contains of 26 sub-components.

\section{Research methodology}

The research objective of this study is: to gain knowledge and understanding with respect to the different steps taken, and, the execution of these steps, in CRAs as part of the JDM process regarding the initiation and/or continuation of international business opportunities by decision makers in Dutch small and medium sized enterprises.

This study is designed according to the rules applicable to exploratory research. 'An exploratory study is a valuable means of finding out "what is happening; to seek new insight; to ask questions and to assess phenomena in a new light' (Robson, 2002). The exploratory research design is used because little is known about the way experts in Dutch SME's go through the JDM process of international business engagement and CRA. In order to generate the necessary knowledge and understanding in this study, qualitative research is executed. 
Qualitative research is defined by Malhotra and Birks (2007) as: “an unstructured, primarily exploratory design based on a small sample, intended to provide insight and understanding". The method of data collection in this study is the use of expert interviews which are held with experts on international business decisions within the populations of this study. The sampling technique used is the nonprobability sampling technique of judgmental sampling. Judgmental sampling is "a form of convenience sampling in which the population elements are purposely selected based on the judgment of the researcher" (Malhotra and Birks, 2007). The following Dutch industries where selected (in between brackets the number of in-depth interviews executed is presented):

- marine supplies (9): companies providing marine equipment to shipyards all over the world,

- horticulture (29): companies growing, both in the Netherlands and abroad, all kinds of crops, flowers, trees, et cetera,

- greenhouse suppliers (20): companies providing all the equipment necessary to build greenhouses, including IT,

- offshore (20): both companies operating offshore as companies supplying equipment to the offshore industry,

- water management (23): all the companies active in the water management industry, including for instance companies involved in the development of harbours and seaports.

These five sectors are categorised as industries by the Dutch Ministry of Foreign Affairs and were selected because they are traditional Dutch industries that have a very good reputation abroad, both for the quality of the products supplied as for the achieved innovations in their specific field. In addition, the companies that operate across borders also realise, already for a large number of years a significant part of their financial results abroad. Hence, these industries can be considered experts in international business.

The data for this research is gathered by executing interviews with experts in JDM in international business opportunities. The interview is structured with the help of a checklist. The questions on the checklist are linked to the research questions and the elements from the conceptual model in order to assure completeness of the checklist. Before the checklist is used in the expert interviews, it is pre tested in order to determine the clarity of the questions to the respondent and whether the complete checklist can be discussed within one hour, which is the time constrained for the expert interviews.

During the interview, the checklist is used as a directive for asking the questions necessary to answer the research questions and, with that, achieve the research objective. In order to assure that, during the interview, the interviewer can focus on the checklist, the answers of the respondent, and the new questions and 
INTERNATIONAL RISK

Henk van den Berg, elaborations the answers of the respondent raises, the interviews are recorded with a Dictaphone. After the interviews the recordings are typed out into transcripts to be used as the basis for the data analysis.

\section{Research findings}

The interviews were analysed based on the interview transcripts and by using the matrix method of qualitative data analysis (in contrast to a statistical method like for instance a factor analysis). The objective of the matrix data analysis is to find patterns in the data the respondents provide during the expert interviews. The first step is to combine all the data gathered, which are the data from the check lists used during the interviews and the recordings from the Dictaphone. Then the recordings are typed out into transcripts, which are used, together with the notes from the checklists as the basis for the final data analysis. Coding of the data is done by first organize the data per checklist question after which the data is analyzed in order to find big chunks of data that seem to share a common denominator. Next the matrix method is used to, identify and measure categories of answers, based on induction of the gathered data. Because the sample is considered to be homogeneous, the matrix contains of one row and one column per question.

The questionnaire focused on four areas, each of them with a series of questions. In addition the respondents were asked what they considered international business to be:

- how respondents actually execute CRA when deciding on international business opportunities, including their definition of international business,

- aspects that may be improved in CRA (adding or removing elements),

- how the respondents perceive the theoretical model in view of their experience,

- what else might be relevant.

The question on what international business is, was answered in an unsurprising way; basically all business outside the Netherlands. However, the motives for doing so ware quite interesting. Respondents recognize two different perspectives in international business. The first perspective was rather reactive, like following customers, recognising export opportunities and response to globalisation of the sector. Respondents called this 'pull', they are pulled towards foreign markets by (potential) customers located abroad. The second perspective is more active, although the motive in the minority of the cases. Respondents called this 'push' where they explore foreign business opportunities in regions they are not active yet. This may be called 'Greenfield internationalization'.

When possibilities arise from the 'push' side, respondents start with analyzing international business opportunities in different countries. The respondents did not mention what overview of countries they use as the basis for their analysis. The 
next step in 'push' is that respondents make a choice to focus on a limited number by the presence of a shipbuilding industry that the respondents companies can RISK supply to.

When possibilities arise from the 'pull' site, respondents mentioned that the only parameter considered is certainty and a limitation of the risk exposure.

In answering the question on what CRA is, we see an emphasis on credit risk. All other risk categories are assessed against credit risk and are roughly divided by the respondents into commercial risk and country risk (or the customer and his/ her environment). Respondents specified country risk as the economic, political and cultural situation in a country. Specific examples of county risks mentioned by the respondents are the prohibition of payments abroad from the country of the customer and the inconvertibility of foreign currencies into the currency of the respondent; the home currency. As the basis for the process of CRA respondents mention that they do not have a standard structure that they always use. They execute CRA as part look at some simple criteria and they do not relate CRA to the strategy of a company as a whole. They only try to answer: what the risk exposure will be when engaging in specific international business opportunities, whether they want to carry the risks themselves and or to what extent they want to share the risks with the customer, an insurance company or another risk sharing partner. When respondents execute CRA, they try to get a 'feeling' for the country. Most of the respondents do that by visiting the country and meet with customers and agents.

Overall the respondents explained that there is only one hard reason not to take an opportunity to engage in international business opportunities and that is when it harms other business opportunities in the future. In general this comes down to not doing business with countries that are under some kind of trade or financial embargo like Iran and Syria.

The focus is on commercial and financial risk, not for instance on economic structure. Political and cultural risk gets much less attention. Respondents do mention the more extreme positions of political risk, such as a country at war or being threatened by international sanctions. However, the overall political stability has proven over and over again to be an important factor for conducting business. The same applies to cultural risk. Indications are that $70 \%$ of failed economic cooperation across borders is due to cultural differences with a total cost of billions of Euros.

Respondents were also asked what can go wrong in the judgement and decision-making process regarding CRA in international business. Respondents mentioned four ways that activities in the process steps are executed incorrect and cause incorrect results in the final decision-making process:

1) The first is that respondents play down the risks involved in international business and focus too much on their willingness to do business. 
INTERNATIONAL RISK

Henk van den Berg,
2) Second, risks are identified by the respondents, but the response to these risks was insufficient. Respondents mentioned that this causes high financial risks and losses, when the risks occurred.

3) Third, information often is incomplete and unclear to the decision makers.

4) Fourth and last, when the process of CRA is not executed completely and in the correct order, than, things go wrong. The order the respondent mentioned is:

- determine the creditworthiness of the potential customer,

- determine the influence of foreign exchange rates on te sales price of the product,

- determine the political situation in the foreign market potential customers are located,

- determine the cultural differences between the home country and the host country,

- inquire information about the country from external sources (for instance industry organizations or the ministry of foreign affairs),

- find, screen, and choose an agent in the foreign market.

The majority of the respondents mentioned that they would like to add steps to the process of CRA like it is currently executed but did not mention specifically what steps. The reason they do not add the steps is because of a constrained in time and means. As a substitute respondents use trust as an argument in CRA. Examples mentioned are trust in local agents and the creditworthiness of big customers.

When confronted with the theoretical model for decision making respondents had difficulty making judgment about the first step; define the problem. They do not experience their motives for engaging in international business as a solution for possible problems which should be the starting point of every decision making process. After the interviewer explained that the problem needs to be considered as a difference between a current situation (or future situation when no change is being made) and a required situation, it became easier for the respondents to answer the question. The majority of the respondents described the problem definition as: the reason they have to start engaging in international business, and is brought in relation to the motives of engaging in international business; follow current customers, find new customers and, find opportunities to grow when the Dutch home market is too small or not growing anymore.

The information of this paragraph is only a very small part of the results and is mainly used as an indication of the main point, a systematic approach to CRA is lacking and its importance is not recognised. In Table 2 we present the model, based on research, once again but now with the results of the judgment and decision-making process in the five sectors. 


\begin{tabular}{ll}
\hline Process steps & Overview of interview responses \\
\hline Define the problem & - Reason / motives to engage in international business \\
\hline - Part of the process of strategy setting
\end{tabular}

Table 2. The model with the results of the

judgment and decision-making process in the five sectors

\section{Initial conclusions}

Decision-making on a heuristic basis with all kind of bias is not per se worse than the application of a scientific model. You cannot prove that money was lost due to this approach of CRA and maybe the traditions of decades or even centuries in these sectors create an attitude, which implicitly covers the most dangerous aspects. However, this appears to be unlikely and for that reason the question becomes how companies may better benefit from this type of research. The decision-making process of the respondents has been summarised in Figure 1. The first conclusion that is drawn is that not all respondents execute formal CRA as part of the decision-making process in international business opportunities. When respondents do execute a CRA, they state to review some simple criteria in an unstructured manner. Secondly, respondents do consider the process of strategy setting and the judgment and decision-making process regarding the initiation and/or continuation of international business opportunities to be two different and separated processes without mutual interaction between them. Consequently, the steps that are executed as part of the judgment and decision-making process lack a decision context (the investment) and decision frame (decision-making model). The process of CRA as implemented by the respondents has a random starting point that is related to the sources of information that are reviewed and not to the 
INTERNATIONAL RISK

Henk van den Berg,

Figure 1.

Decision-making by respondents strategy of the organisation. Thirdly, instead of using objectives to determine the information that needs to be gathered and judged by the respondents, the process is reversed. Respondents review different sources of information like country reports, expert judgment and local parties and determine, based on the information that is presented to them, which attributes represents country risk and, by reviewing the measurement of the attribute, whether the risk exposure is acceptable to them or not. And finally, the outcome of the process of CRA is hardly ever an obstacle in the decision that is taken regarding the initiation and/ or continuation of international business opportunities. The only reason to reject international business opportunities is when the country or area the opportunity is located, is at war or when there are international trade restrictions, like the case with Iran. In all other cases, the country risk exposure identified by the respondents, is rolled off on the customer in drawing up the tender and the terms. For instance, high credit default risk is rolled off on the customer by offering in the tender that the customer has to pay a certain percentage upfront or carry the cost for a letter of credit.

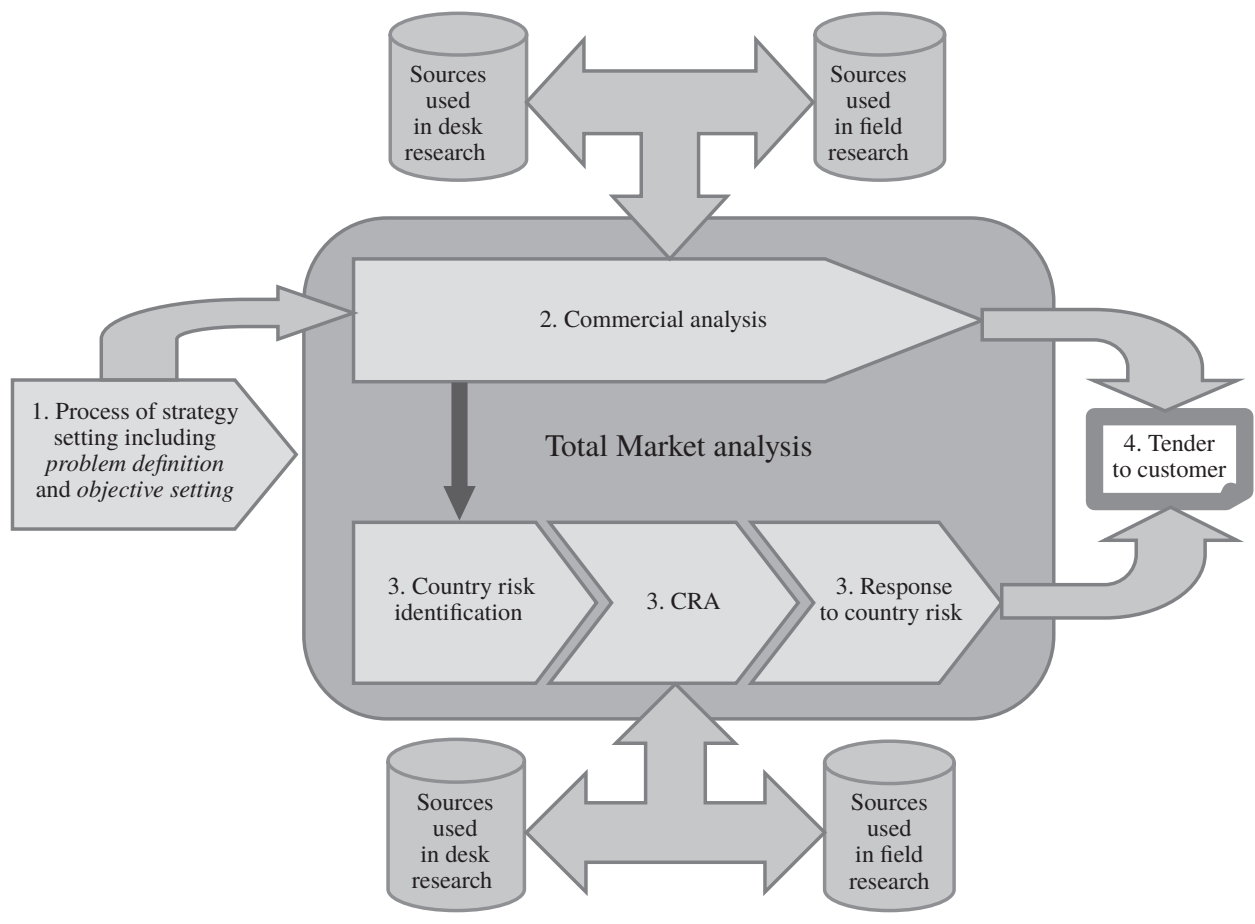

If we look at a more favourable model for CRA in the sense of a more structural approach to all aspects involved in doing business in another country and resulting in a calculated risk, we may consider Figure 2. However, the 
implementation of that model is still a far cry off, particularly for the SMEs with limited time and overhead, combined with the need to grasp every possible opportunity. In addition the different elements of this model need to be elaborated and converted into specific questions or tasks to ensure that the process is being done correctly. Furthermore, the model of Figure 2 needs to be incorporated in the whole of the judgment and decision-making process. To clarify this idea on the way forward we may take a comparable example in a different field with much less consequences. In order to stimulate students to go for traineeships abroad or to do their thesis research in another country, we developed an app for the iPad, Abroad! (not yet in the Appstore yet). In the first part students are asked to fill out (on screen) a series of tables, asking for the formal requirements for internship or thesis; are they allowed to start that part of their studies? In the second part they answer questions on the country they are going to, in particular

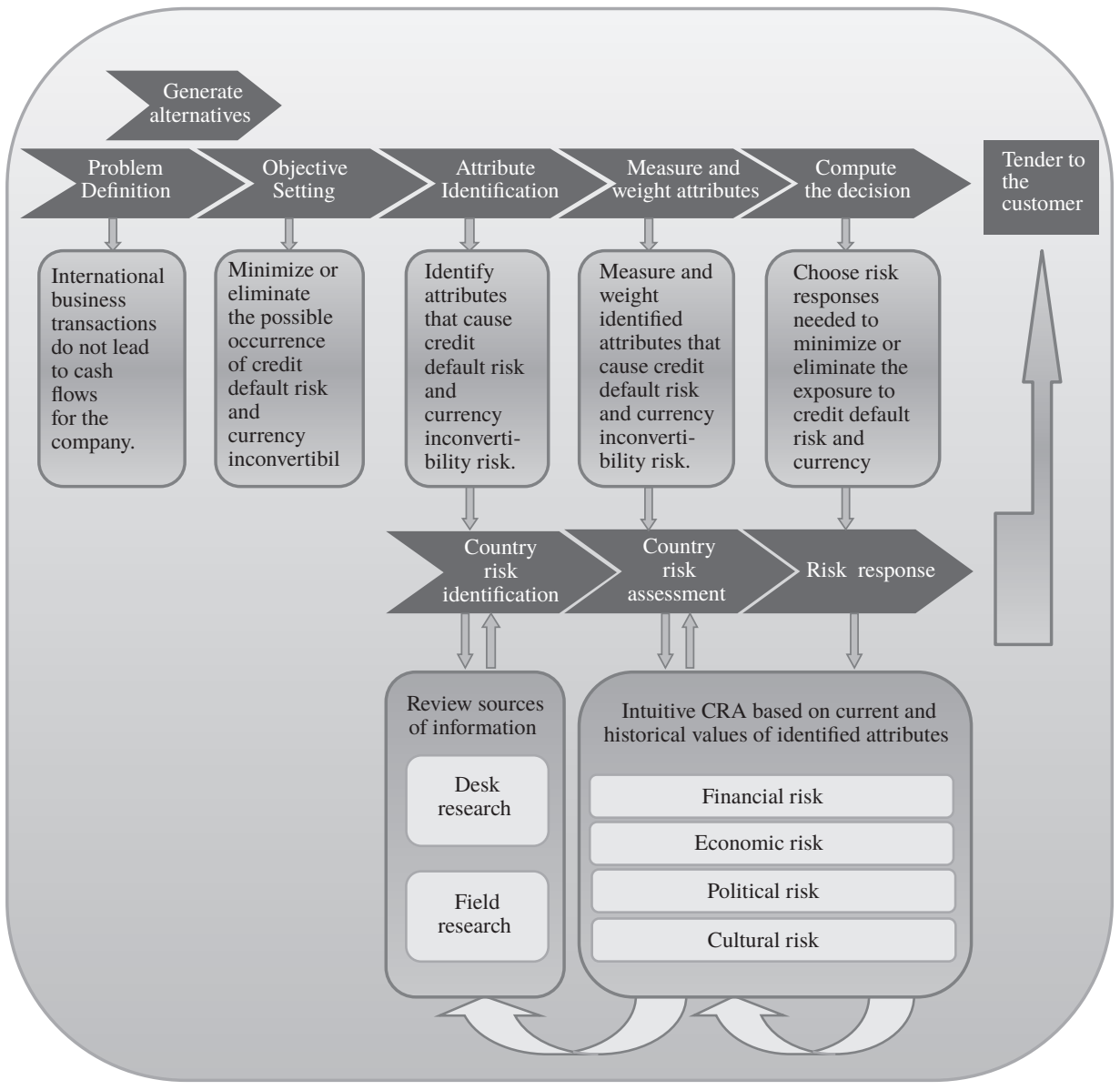

INTERNATIONAL RISK

Henk van den Berg,

Figure 2.

Model of CRA as part of judgement and decision-making 
INTERNATIONAL RISK

Henk van den Berg, on politics, economics and culture. Thirdly, they face a series of questions on their host organisation and intended activities. Finally the paper trail is established, ranging from travel details through addresses, contact persons and how they may be reached 24/7. All this information results in a report through which the student may get the necessary approval.

Whether an app, a website or just a simple paper questionnaire, the idea remains the same: to give the entrepreneur a specific tool which assures him or her that $\mathrm{s} / \mathrm{he}$ has done what can be done in the field of country risk assessment. This may even turn into an advantage in discussions of insurance coverage, like insurances are asking luxury car owners on all kind of anti-theft equipment.

\section{Follow-Up}

Like in any other research, this research left us with more questions than we started with. First of all, the large extent to which decision makers rely on their feelings of trust and their emotion when making judgments about country risks and executing international business suggests the use judgmental heuristics. Within the scientific field there is a large amount of theory available about the use of judgmental heuristics by individuals when confronted with situations of uncertainty (for instance the work Kahneman and Tversky have been doing since 1971). This made us curious whether we can develop multiple experiments in order to determine whether the group of respondents we focused on in the research and described in this paper, use judgmental heuristics and to what extent that leads to bias and sub-optimal choice behaviour.

Second, because this research is executed within Dutch SME's, we wonder what the influence of culture is on the way decision makers make judgments about country risks in decisions concerning international decision making. For that we are exploring the possibilities to duplicate our research in different cultures to investigate whether there are differences between judgment about country risks and whether these differences in judgment and choice behaviour can be assigned to cultural difference.

\section{References}

Ahlstrom, D., Bruton, G.D. (2010), International Management. Strategy and Culture in the Emerging World, Thomson, London.

Baird, I.S., Thomas, H. (1985), “Toward a Contingency Model of Strategic Risk Taking”, Academy of Management Review, Vol. 10, No. 2, pp. 230-43.

Bouchet, M.H., Clark, E., Groslambert, B. (2003), Country Risk Assessment. A Guide to Global Investment Strategy, John Wiley \& Sons. Inc., Hoboken, NY.

Dyck, B., Neubert, M.J. (2009), Principles of Management, Thomson, London.

Goodman, P., Wright, G. (2009), Decision Analysis for Management Judgment, John Wiley \& Sons Ltd, Chichester. 
Groenland, E.A.G. (2003), Research methodology, Business University Nyenrode, BreuINTERNATIONAL kelen.

Hardman, D. (2009), Judgment and Decision Making, BPS Blackwell, Chichester.

Malhotra, N.K., Birks, D.F. (2007), Marketing Research: An Applied Approach, Pearson Education Limited, Edinburgh.

Olsson, C. (2002), Risk Management in Emerging Markets, Financial Times and Prentice Hall, London.

Ricardo, D. (1817), The Principles of Political Economy and Taxation, John Murray, London. Robson, C. (2002), Real World Research, Blackwell, Oxford.

Salvatore, D. (2011), International Economics. Trade and Finance, John Wiley, New York.

Smith, A., (1937), The Wealth of Nations, The Modern Library, New York.

White, C., Fan, M. (2006), Risk and Foreign Direct Investment, Palgrave MacMillan, New York. 